\title{
Sanatta Esinlenme Süreçleri, Beethoven'dan Tolstoy'a Tolstoy'dan Günümüze: Kreutzer Sonat
}

\section{Zoumroud Alieva*}

\section{Özet}

Makalenin amacl, "Kreutzer Sonat» olarak da bilinen, Ludwig Van Beethoven'ın keman ve piyano için yazdığı 9 numaralı sonatının, dünyadaki bir çok sanatçının eserlerinin yaratılma süreçlerini nasıl etkilemiş olduğunu irdelemektir. Buna en önemli örnek olarak Lev Tolstoy'un 1889 yilında yayımladığı aynı isimli romanı 'Kreutzer Sonat' ı gösterebiliriz. Bu uzun öykü mutsuz bir çiftin hayatını yok eden yıkıcı bir aşk, yakıcı bir öfke ve öldürücü bir kıskançlığı konu alır. Tolstoy'un bu eseri Rus edebiyatında 19.yüzyıl ayrıcalıklı sınıfların kültüründe kadının rolünü, aile düzenini sorgulayan, aşk, evlilik ve kadın cinselliği ile ilgili farklı düşünceleri ifade eden ve zamanında uygunsuz olarak algılanan bir eser olarak tanınır. Lev Tolstoy'un uzun öyküsüne Beethoven'ın Kreutzer Sonat'ı ile aynı ismi vermiş olması Beethoven'ın müzikte yaptığı devrimsel tavıra adeta bir göndermedir. Edebiyatçı kimliğiyle Tolstoy'un, birkaç düzeyde "Kreutzer» kelimesine çeşitili anlamlar yüklediğini görmekteyiz. Eserin, yaratma sürecinde biçimsel, dönemsel, düşünsel ve benzeri tüm engelleri aşan bir atılımla sanatta özgür ve özgün düşüncenin gelişmesinde Beethoven'nın atılımına benzer bir çizgi izlediğini göstermiştir. Tolstoy'un bu eserinin gerek isminin seçilmesinde, gerekse içeriğindeki tavırda, müziğe bu kadar vakıf olmasının da rolü vardır. Yakın arkadaşı Nikolai Rubinstein'ın Tolstoy'un bir sorusuna cevap olarak Beethoven'ın Kreutzer Sonatı́nın çağının kalıplarını kıran birinci bölümüne dikkat çekmesinin bu esinlenmede büyük bir rolü olduğu düşünülür. Makale öncelikle bu iki büyük sanatçının eserlerinin ortaya çıkış ve tarihte yer alış süreçlerini mercek altına alacak ve yine Beethoven'in sonatın müzikal kalıplarını kırıp, müzik dünyasında önce derin şaşkınlık ve daha sonra hayranlık yaratan Kreutzer Sonatı'nın, tarihte diğer sanatlarda da hiç bitmeyen yansımalarına ve bundan esinlenmiş diğer sanat eserlerine dikkat çekecektir.

Anahtar Kelimeler: Beethoven, Tolstoy, Kreutzer Sonat, Sanatta Esinlenme

Öğretim Elemanı, İstanbul Üniversitesi, Devlet Konservatuvarı, zoumroudaliyeva@hotmail.com. (Makale Gönderim Tarihi: 29.01.2018; Makale Kabul Tarihi: 10.04.2018) (ORCID ID: 0000-0002-3515-6991).

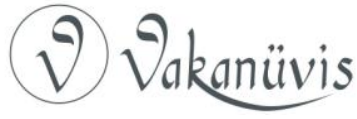




\title{
Inspiration Process, From Beethoven To Tolstoy, From Tolstoy To Today: Kreutzer Sonata
}

\begin{abstract}
The purpose of this article is to examine how Ludwig Van Beethoven's $9^{\text {th }}$ Violin and Piano Sonata, also known as Kreutzer Sonata, has influenced the creation process of the works of many artists in the world. The best example to this is probably Lev Tolstoy's long story named also "The Kreutzer Sonat" written in 1889. This long story is about destructive love, burning anger and deadly jealousy that destroy the life of an unhappy couple. This important work by Tolstoy has been seen as an attempt to question the role and the place of the woman, as well as the way the society expected or understood their relation to love, to marriage and to family life in the $19^{\text {th }}$ century aristocratic culture and religion. The fact that Lev Tolstoy has given to his famous long story the same title as Beethoven's Sonata is almost a tribute to Beethoven's revolutionary demeanor in his "Kreutzer Sonata". Tolstoy the author, has probably attributed several implications and meanings to the word "Kreutzer" which can always be analyzed in literature. The creative process of this long story that transcends all the formal, periodical, and intellectual obstacles makes us aware of the fact that Tolstoy has followed Beethoven's attitude as a free and creative and protest artist. Nikolai Rubinstein, a close friend of Tolstoy's, has probably played an important role by drawing Tolstoy's attention to the first part of Beethoven's "the Kreutzer Sonata", which breaks the accepted patterns of the sonata form. Beethoven's Sonata and Tolstoy's long story bearing the same name; "Kreutzer Sonata", both in their ways, continue to affect the creativity processes of young artists' minds all over the world. Thus other works of artists inspired by "The Kreutzer Sonata" will be reviewed and the reflections of the artworks and the reflections in the art world will be examined but never the less this article focuses primarily on the emergence and historical paths of both of the works of the same name of these two great artists: "Kreutzer Sonata," and acknowledges that Beethoven's composition in the first place, has led the way by its revolutionary attitude and its artistic beauty to the inspiration of many artists of all fields until present times.
\end{abstract}

Keywords: Beethoven, Tolstoy, Kreutzer Sonata, Inspiration In Arts

\section{Giriş}

Esinlenme - kişinin içsel faaliyetlerinin arttığı, duygusal yükselme yaşandığı, insanın ruhen ve bedenen gerilim yaşadığı psikolojik bir

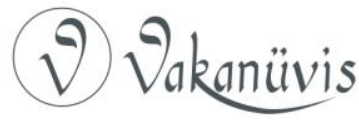


durumdur. Esinlenme, yaratıcı sürecin ön koşullarından biridir ve hafızayı, hayal gücünü ve yoğun düşünceyi seferber ederek büyük bir dikkat yoğunluğuyla ilişkilendirilir. Esinlenme, yaratıcı sürecin ana unsurudur.

Esin kaynağı sevgi, hayaller, doğa, kişinin içsel yaşamı ve buna benzer durumlar olabilir. Yine bu esin kaynağı başka sanatçılar tarafından daha önce oluşturulmuş eserler de olabilir. Bu tür olgular tüm sanatlar için geçerlidir.

Insanlık tarihi boyunca özellikle müzisyenler ve besteciler edebi eserleri ve onların konularını esin kaynağı olarak kullanmışladır. Ancak bir edebi esere bir müzikal eserin esin kaynağı olduğu oldukça nadir görülen bir durumdur. Bunun bilinen örneklerinden biri Beethoven'ın Kreutzer Sonatı'nın, Lev Tolstoy'un Kreutzer Sonat adlı uzun öyküsüne esin kaynağı olmasıdır. Daha sonraları Lev Tolstoy'un eseri de birçok eserin doğmasına esin kaynağı olmuştur. Tolstoy'un etkiledikleri sanatçıların eserleri arasında, Fransız ressam Rene Xavier Prinet'in "Kreutzer Sonat" tablosu (1901), Çek besteci Janacek'in "Yaylı Quartet No. 1" (Kreutzer Sonata) eseri (1923), Hollandalı piyanist ve yazar Margariet de Moor'un "Kreutzer Sonata" kitabı (2005), Amerikalı Rita Dove'un "Sonatta Mulattica" kitabı (2009), Kongolu Emmanuel Dongola'nın "Kreutzer Sonata" kitabı (2017), birçok film ve piyesler örnek gösterilebilir. Müziğin ve edebiyatın evrenselliğini ve yazıldığı günden günümüze yansımalarını görmek mümkündür.

Bu makalenin amacı, çağının kalıplarını kıran olağanüstü müzikal eserin Tolstoy'un aynı adlı aykırı romanının yazılmasına ne şekilde esin kaynağı olduğunu ve dünya çapındaki sanatçılara olağanüstü eserler yaratmaları için esin kaynağı olmaya devam ettiğini göstermektir.

\section{Yaratılış Hikayesi}

İki çalgı için konçerto olarak anılan Kreutzer Sonat Ludwig Van Beethoven'ın en ünlü salon eserlerinden biridir. Sonat, bestecinin en üst düzeyde virtüözitesinin başyapıtıdır.

Sonat üç bölümden oluşur ve yaklaşık 43 dakika sürer: Adagio sostenuto - Presto - Adagio (15 dakika); Andante con variazioni (18 dakika); Presto (10 dakika).

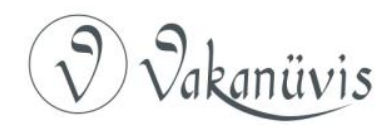


Beethoven, isimli sonatı olan Kreutzer'i 1803 yılında bestelemiştir. Başlangıçta sonat, ünlü İngiliz keman virtüözü George Bridgetower'a adanmıştır. Prömiyeri George Bridgetower ile birlikte 24 Mayıs 1803 tarihinde sabah sekiz de Augarten Viyana'da gerçekleşmiştir (o devirde Viyana'nın saray adetlerine göre konser saati sabah sekizdedir). ${ }^{1}$ Nedenlerini ilerleyen paragraflarda açıklayacağımız gibi bu sonatın icrası dinleyicileri üzerinde beklenmedik bir etki yaratmıştır. Bu eser 1805 yılının Nisan ayında 'R.Kreutzer' ithafıyla yayınlanmıştır. Hala hakkında düşündüren ve konuşulan bu sonat günümüzün konser sonatları içerisinde önemli bir yer tutmaktadır.

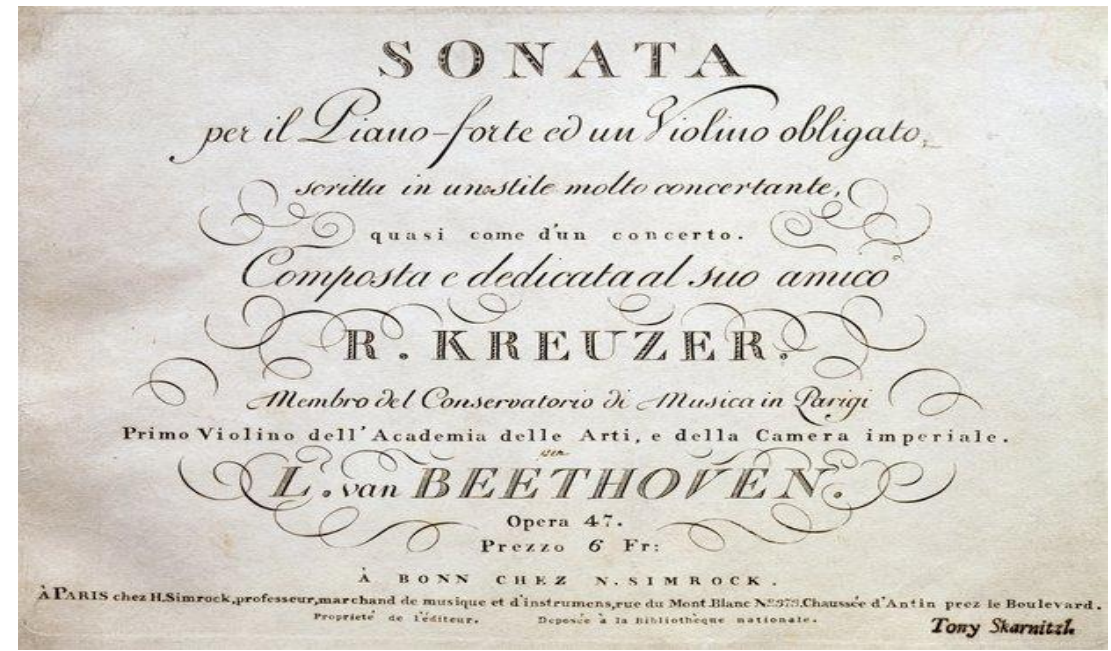

Şekil1: Beethoven Kreutzer Sonat'ın ilk baskısı. ${ }^{2}$

L. Van Beethoven keman-piyano sonatlarında iki çalgının rolünü eşitlemiş; tüm müzikal materyallerin yoğun bir diyalog halinde paylaşılmasını sağlamıştır. Bunun yanı sıra, sonat yazısında iki çalgı için de teknik ve virtüözite seviyesini ciddi bir şekilde yükseltmiş ve türün süresini önemli bir ölçüde uzatmıştır. Bunun en güzel örneği, op. 47 Kreutzer Sonatı'nda görülmektedir. Bu eser, keman-piyano sonatını bambaşka bir boyuta taşımıştır.

\footnotetext{
${ }^{1}$ Larissa Kirilina, Beethoven, Moskova, 2015, s.34.

http://www.classicfm.com/composers/beethoven/guides/key-people-beethovensmusic-and-life/kreutzer-sonata-beethoven/(03 Ocak 2018).
}

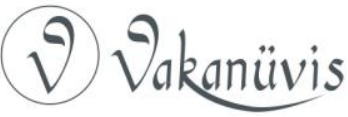


Beethoven Kreutzer Sonat'ı prömiyerini yaptığı Bridgetower'a adamıştır. Ancak daha sonra bilinmeyen nedenlerle bundan vazgeçmiş bu eseri fransız kemancı, besteci ve şef Radolphe Kreutzer' a adamıştır ve öyle yayınlanmıştır. Başka kaynaklara göre, bu eserin halka daha çekici gelebilmesi için Kreutzer'in isminin bilinen bir isim olması nedeni ile tercih edildiği ve sonatın Kreutzer'e adandığı ifade edilmektedir. ilginç olan ise Kreutzer'in bu eseri hiç çalmamış olmasıdır. Ancak Kreutzer'in adı Beethoven'ın bu çok önemli sonatı ile bağlanmıştır.

Bridgetower, Beethoven ile Prens Karl Lichnowky'nin evinde tanışmıştır. Bridgetower'la ilgileri karşıııkı olan Beethoven yakınlaşmaya başlamışlardır. Bunun üzerine Beethoven, Bridgetower için dönemin ünlü salonlarında birçok konserler ayarlamış, onun büyük bir destekçisi ve arkadaşı olmuştur. Almanya'nın Bonn şehrindeki Beethoven'ın evinde Kreutzer Sonat'ın el yazması notasında sağ üst köşede ki hitap kısmında "Sonata mulattica composta per il Mulatto Brischdauer gran Pazzo e compositore mulattico" yazmaktadır. Bunu "Büyük soytarı, çılgın ve melez besteci Bridgetower için yazılmıştır." şeklinde türkçeye çevirmek mümkündür. ${ }^{3}$

\section{Tolstoy ve Kreutzer Sonat}

Kreutzer Sonat, hem doğrudan hem de dolaylı olarak müzik camiasını, diğer sanatsal ve entelektüel formları uzun süre büyük bir etkide bırakmıştır. Bunun önde gelen örneği Lev Tolstoy'un 1889' da yayınlanmış kitabı olan Kreutzer Sonat'dır. Beethoven'ın Kreutzer Sonat prömiyerinden $86 \mathrm{yıl}$ sonra Tolstoy'un kendi eserini yayımlamasıyla eser, büyük bir çalkalanma yaşatmış ve popülarite kazanmıştır.

Moskova Konservatuarı'nın kurucusu ve müdürü olan Nikolai Rubinstein, bir gün Tolstoy kendisiyle konuşurken, keman ve piyano için yapılan eserlerden hangisinin kendi görüşüne göre en önemli olduğunu sorduğunu hatırlar. Rubinstein düşünmeden Beethoven'ın Kreutzer Sonatı diye cevap verir. Ardından Beethoven'ın eseri ile aynı

\footnotetext{
${ }^{3}$ Dirk Göttsche, Remembering Africa The Rediscovery of Colonialism in Contemporary German Literature, New York 2013, s. 242.
}

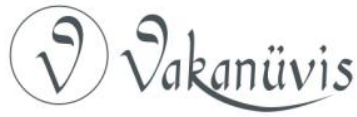


adını taşıyan Tolstoy'un hikâyesi dünyada yayınlanmış ve farklı tepkiler ile karşılaşmıştır. ${ }^{4}$

Eserin yazarı ve adı dışında da kendine çeken bazı olaylar yaşanmıştır. Bunlardan biri yayınlandığı dönemde Rus İmparatorluğu tarafından sansürlenmesidir, Amerika'da ise doğrudan yasaklanmasıdır. Tolstoy, bu eseri yayımladığında toplumu ahlaksızlığa yöneltmekle suçlanmıştır. Lev Nikolaeviç'in eşi Sofya Andreevna Tolstaya (1844-1919) Çar Aleksandr III (1845-1894) tarafından kabul edildikten sonra, Çar isteksiz bir şekilde 13 ciltlik hikâyenin tefrika edilmesine izin vermiştir. Hikâyenin yasaklanmış olması okurlar için çekiciliğinin artmasına neden olmuştur. Kitap, Amerika'da illegal olarak satılmakta bir yandan da gazetede bölümler halinde yayınlanmaktaydı. Öykünün okunmasını önlemek amacıyla Ulusal Posta Servisi Kreutzer Sonat'ı tefrika eden gazetelerin dağıtımını engellemiştir. ${ }^{5}$

Tolstoy'un Kreutzer Sonatı ünlü çağdaşlarından son derece olumsuz ve anlaşılmayan yorumlar almıştır. Bu nedenle, Tolstoy, Gogol, Gorky, Dostoyevsky, Bunin ve Turgenev gibi birçok Rus yazarın hikâyelerini İngilizceye tercüme eden Amerikalı yazar ve tercüman Isabel Hapgood, Tolstoy tarafından yaratılan başkahramanın aile yaşantısına uygunsuz olarak tanımlanmıştır ve yine görüşüne göre, tüm hikâye iki kişinin vahşi tutkuları ile ilgili acımasız ve kaba bir saldırıyı temsil etmektedir. Hapgood'a göre yoğun bir şekilde birçok kısım silinse bile, hikâyenin tercümesinin imkânsız ve uygunsuz olduğunu düşünmektedir. Ancak yazar, herşeye rağmen 1890 yılında hikâyeyi tercüme etmiştir. Tolstoy'un hikâyesi ile tanışan Anton Çehov, hikâyeyi bastırmadan önce aşk, evlilik ve aile ile ilgili Tolstoy'un belirli fikirlerine karşı çıkmıştır. Ancak bu eksiklikler, rüzgârda uçuşan tüyler gibidir; hikâyenin genelinde onlar hiç fark edilmez, fark etseniz bile, sadece izlerden arınmamış, kusurlu insanların tüm bunların mevcudiyetinden kaçınmadığı için yalnızca rahatsız olursunuz" diyordu Çehov. ${ }^{6}$

\footnotetext{
${ }^{4}$ Svetlana Kirillova, Kreutzer Sonata, İskusstovo, Sayı 24, 2007.

5 Matthew Oswin, Beethoven's 'Kreutzer' Sonata: Nineteenth-century Art of Arrangement-One Piece Three Ways, New Zealand 2013, s. 6.

${ }^{6}$ Peter Ulf Moller, Postlude to The Kreutzer Sonata: Tolstoy and the Debate on Sexual Morality in Russian Literature in the 1890's, Leiden, New York: E.J. Brill, 1988, s. 103.
}

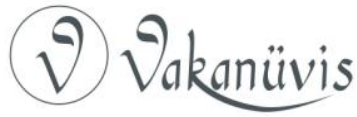


Tolstoy, bu dönemde tanıdığı, tanımadığı birçok kişiden Kreutzer Sonat'ın öyküsünde anlatılmak isteneni açıklamasının istendiği birçok mektup üzerine "Kreutzer Sonat'ın Devamı" ya da kitabın sonunda bulunan "Yazarın Romana Dair Yazısı" olarak bilinen savunma metnini yazmıştır. Yukarıda anlatılanlarda da görüldüğü gibi Tolstoy kendi çağının alışıımış sosyal kalıplarını kırarak Beethoven gibi sanatını aşmaya çalışmıştır. Belki de işte tam bu noktada sanatsal yaklaşım açısından yolları kesişmiştir. Müzikle yakından bağlantılı olan Tolstoy, geniş müzik bilgilerine sahip olmakla birlikte keman ve piyano çalmaktaydı. Hikâyesinin ana karakteri olan Vasily Pozdnyshev'in ağzından şunları yazıyordu: "Müzik, kendimi unutturuyor, gerçek konumum, beni başka bir yere götürüyor, benim olmayan bir konuma müziğin etkisi altında hissetmediğim şeyleri hissettiğimi zannediyorum ve anlamadığım şeyleri anladığımı zannediyorum". ${ }^{7}$ Besteci ve müzikolog Tolstoy'un oğlu Sergey Tolstoy da (1863-1947), anılarında babası kadar güçlü bir şekilde müziği hisseden başka biriyle hiç karşılaşmadığını yazmıştır. ${ }^{8}$

Tolstoy'un toplam iki yıl boyunca ara vererek yazdığı ve en az dokuz kez değiştirdiği bu hikâyenin konusu, karısını kıskançlık krizi ile öldüren bir kocanın itirafı hakkındadır. Trende, başkahraman Pozdnyshev, aşkla ilgili genel bir konuşmaya karışarak, gençliğinde dikkatsizce çapkınlık yaptığını anlatır ve kadınların elbiselerinin erkek arzularını uyandırmak için tasarlandığından şikâyet eder. Erkeklerin, kadınları arzu objesi olarak algıladıkları sürece, hiçbir zaman eşit haklara sahip olamayacağını iddia etmektedir. Pozdnishev karısının öldürülmesine yol açan olayları anlatıyordu; kendisi yoksulluğu veya bağlantıları nedeni ile evlenmemiş ve ayrıca evlendikten sonra tek eşli olma niyetinde olduğunu anlatmaktadır. Bu sebeple gururun haddi hesabı yoktu. Ancak, her şey ters gitti, balayı gerektiği gibi olmadı. Üçüncü veya dördüncü günde Pozdnishev karısını canı sıkılmış buldu, neler olduğunu sordu, sarıldı. Karısı ağlayarak nasıl anlatacağını bilemedi. Karısının canı sıkkındı ve üzgündü. Yüzünde de beklenilmedik bir soğukluk ve düşmanlık vardı. Pozdnishev bu düşmanlığın geçici bir

\footnotetext{
${ }^{7}$ G-Ken, Anton, Beethoven Jizn', Lichnost', Tvorchestvo, Saint Petersburg 1910, s. 79.

8 Irina Yemelyanova, "Muzyka v jizni L'va Nikolayevich Tolstogo", http://muzruk.info/?p=5152 (August 14, 2017).
}

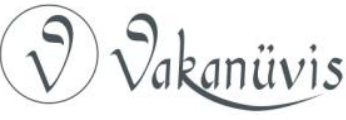


durum olmadığını, normal bir durum olduğunu anlamıyordu. Ancak daha sonra bir takım tartışmalar meydana geldi ve Pozdnishev evliliğin çok hoş bir şey olmadığını hissetti, hatta tam tersi çok ağır bir şey olduğunu düşündü, ancak bunu ne kendine ne başkalarına itiraf etmek istemiyordu.

Karısı kemancıya hayrandı ve birlikte Beethoven'ın Kreutzer Sonatını çalmaktaydılar. Pozdnishev içinde fırtınalar kopartan kıskançlığı zapt edip, gizleyerek iş için evden ayrılmıştır. Döndüğünde onları birlikte görecekti. Müzisyen kaçıyor, Pozdnishev ise karısını hançer ile öldürüyordu. Tolstoy'un hikâyesi üç temel motif içermektedir: müzikal zevk, engellenmemiş cinsel arzu ve şiddetli kıskançlık. Hikâyede, evlilik, ihanet, eşlerin ahlaki ölümü, kadınların hak ve statüsü gibi konulara değinilmektedir ve bu konular günümüzde de tüm dünyada geçerliliğini korumaktadır. Beethoven'ın sonatından esinlenen ve o günün toplumunun değerlerine ters düşen, dışlanan bu öykünün toplum üzerinde yarattığı sarsıcı etkileri bugün kavramakta zorluk çekebiliriz. Ancak bu durumla Beethoven'ın kendi yaşadığı devirde de yine toplumun alışkanlıklarına ve kalıplarına ters düşen bir eseri besteleyip icra etmesinin getirdiği tepkilerle de bir paralellik kurabiliriz. Bize bu tepkiyi hissettiren Tolstoy'un kendisidir. Lev Nikolaevich, hikâye kahramanı Vasily Pozdnyshev adına şunları yazıyordu: "Onlar, Beethoven'ın Kreutzer sonatını çalıyorlardı. Illk prestoyu biliyor musun? Biliyor musun?" diye haykırdı. "Bu! ... Korkunç bir şey bu sonat... Genelde de korkunç bir müziktir. ... Bu, bu müzik, müziği besteleyen kişinin ruh haline doğrudan götürüyor beni. Kreutzer sonatını yazan kişi - Beethoven, neden bu ruh halinde olduğunu biliyordu... İşte bu yüzden müzik bazen o denli korkunç oluyor ve insanı derinden etkilemekteydi."

O dönemde bu müziği dinleyen ve etkilenen Tolstoy, Beethoven'ın Kreutzer Sonat'ı hakkındaki hislerine kitabın baş kahramanı asilzade Pozdnyshev'in ağzından şu şekilde yer vermiştir: "..., hiç değilse şu Kreutzer sonatın dekolte giyimli kadınların hazır bulunduğu bir salonda çalınması olacak şey midir? O prestoyu çalmak, sonra alkışlamak, daha sonra dondurma yemek, o arada son dedikodulardan söz etmek olur mu? Bu tür müzikler ancak bilinen, önemli, anlamlı durumlarda, bu

${ }^{9}$ Lev Tolstoy, Kroyçer Sonat, Ergin Altay (Çeviren), İstanbul, 2015, s.148.

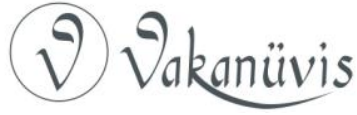


müziğe uygun ve bilinen davranışlarda bulunulması istendiğinde çalınabilir... Çalarsınız müziği onun sizi yönlendirdiği şeyi yaparsınız. Yoksa yerine de, zamanına da, uygun olmayan durağan bir enerjiyi, duyguyu uyandırmak insanı felakete sürüklemekten başka bir şeye yaramaz...". ${ }^{10}$

Daha sonra Beethoven'ın Kreutzer Sonata'ı ile ilgili Tolstoy "Müziğin erotik duygular uyandırmaktaki gücünün (ona göre, tehlikeli bir güçtür bu) en üstün örneklerinden biridir." sözlerini sarf etmiştir. ${ }^{11}$

Sovyet edebiyat eleştirmeni ve Tolstoy'un biyografi yazarı Nikolai Gudziy ise "Hikâye sadece psikolojik değil, aynı zamanda ayrıcalıklı sınıfların aile düzenine karşı yöneltilen toplumsal ifşa içermektedir" sözlerini sarf etmiştir. ${ }^{12}$

1953 yılında, New York'ta yayınlanan "Baba. Lev Tolstoy'un Hayatı" kitabında, Tolstoy'un kızı Alexandra Tolstaya hikâyenin doğuşunu ve yazılışını aydınlatmaktadır. 1888 yılının sonbahar akşamında Moskova'da Tolstoy'un Khamovniki evinde gençler bir kez daha Beethoven'ın Kreutzer Sonatı'nı çalmışlardır. Tolstaya'nın misafirleri, Tolstoy'un Kreutzer Sonatı'nın motiflerine göre hikâye yazmış olsaydı, ressam llya Repin bu hikâyeyi resimleseydi, aktör Vasily Nikolayevich Andreyev-Burlak ise bunu sahnede oynasaydı, çok iyi olacağı konusunda konuşmuşlardır. Böylece, Tolstoy'un romanı en başta sanat işbirliğinin bir parçası olarak görülmekteydi. "Bu tür üç sanatın birleşmesinden harika bir şey olurdu," - diye yazmış Tolstoy. Fakat ne yazık ki bu düşüncesi gerçekleşemedi çünkü bunu paylaştığı sanatçılardan aktör Andreyev -Burlak kısa süre sonra hayatını kaybetti. Tolstoy'un biyografi yazarı Pavel İvanovich Biryukov'un tahminine göre, Yulia Liasotti ve Sergey Tolstoy tarafından o gece çalınan Beethoven'ın sonatı bu hikâyenin yazılmasına sebep olmuştur. Buna karşıık, Tolstoy'un eşi Sophia Tolstaya kendi günlüğünden hatırladığı kadarıyla, hikâye oluşturma fikri, eşinin ihaneti hakkındaki mutsuz

${ }^{10}$ Tolstoy, a.g.e., s. 150.

11 Lewis Lockwood, Beethoven: Müzik ve Hayat, Ebru Kılıç (Çeviren), İstanbul 2013, s. 149.

12 Aliandra Antoniacci, The Crisis of the Russian Family in the Works of Dostoevsky, Tolstoy and Chekhov, Canterbury Üniversitesi Rusya Araştırmaları Enstitüsü Basılmamış Doktora Tezi, Canterbury 2015, s. 266.

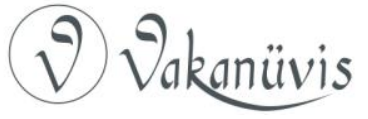


hikâyeyi tren istasyonunda tanımadığı bir beyle paylaştıktan sonra ortaya çıkmıştır. Tolstoy günlüğüne şöyle yazmıştır: "Yani temel düşüncede, daha doğrusunu söylemek gerekirse "Kreutzer Sonatı'nın" duyguları, kadınların cinsel gereksinimlerinin depresif hali hakkında, komik bir dille ve harika bir içerikle mektup yazan Slav bir kadına aittir". ${ }^{13}$

Tolstoy'un sonatı, eşi Tolstoya tarafından da acı bir şekilde benimsenmiştir. 1891 yılı kış aylarında günlüğünde: “...Ben, tüm kalbimle, bu hikâyenin bana yönlendirildiğini hissettim, aniden beni yaraladı, tüm dünya gözünde beni aşağıladı ve aramızdaki son aşkı mahvetti" yazmıştır ${ }^{14}$ Ancak 1994 yılında "Ekim" dergisinde yayınlanabilen "Kimin suçu?" hikâyesi (Lev Tolsoy'un "Kreutzer sonatı" hakkında), Tolstoya tarafından eşinin hikâyesine vermiş olduğu bir nevi cevaptı. Kadının hikâyesinde, aynı zamanda genç eşlerin geri dönüşü olmaz bir şekilde, trajediye doğru giden hayatları anlatılmıştır. "Kadınla erkek arasındaki sevgi farkını göstermek istedim. ${ }^{15}$ Erkeklerde ilk planda - maddiyat sevgisi; kadınlarda ise ilk planda - idealist, aşk hikâyesi, şefkat, daha sonra cinsel uyarı geliyor," diyordu Tolstaya anılarında. Bu anılar yaşanılan devrin aile yaşantısı ve kadınlarla ilgili görüşlere en büyük tanıklığı yapmaktadır. ${ }^{16}$

Tolstoy'un hikâyeyi yazmasından yüz on bir yıl sonra, 2001 yılında Tolstoy'un orijinalliğinden esinlenen Hollandalı piyanist ve yazar Margriet de Moor "Kreutzer sonatı, aşk hikâyesi" eserini yayınlamıştır. Beethoven'dan esinlenen Tolstoy'un hikâyesi, her şeyden önce hikâye yorumları ve dünyanın dört bir yanında kendi versiyonlarını yazmak isteyen bu ve benzeri edebiyatçılara esin kaynağı olmuştur.

\section{Janacek, Prinet ve Kreutzer Sonat}

\footnotetext{
13 Tolstoya, Alexandra, Otec. Jizn' L'va Tolstogo, Moskova 2001, s. 281-282.

${ }^{14}$ Anna, Stroganova, "Neizdannaya povest' Sofyi Andreyevny Tolstoy "Ch'ya vina?» v novom literaturnom sezone", http://ru.rfi.fr/kultura/20100823-neizdannaya-po1vestsofi-andreevny-tolstoi-chya-vina-v-novom-literaturnom-sezone (14 Ocak 2010).

${ }^{15}$ Alison Flood, Sofia's revenge: short stories by Leo Tolstoy's wife and son are published with The Kreutzer Sonata, https://www.theguardian.com/books/

2014/oct/30/sofia-tolstoy-kreutzer-sonata-variations-published-in-english (14 Ocak 2017).

${ }^{16}$ Tolstaya, a.g.e., s. 282.
}

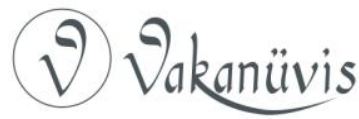


Tolstoy'un Kreutzer Sonat eserinden esinlenerek oluşturulmuş en ünlü müzik eserleri "Piano Trio" ve "Yaylı Quartet No:1"dir. Leos Janacek, Tolstoy'un eserinden öyle etkilenmiştir ki, 1908 yılında yazdığı ancak yayınlanmadığı için şuan kayıp olan "Piano Trio" eseri için esin kaynağı olmuştur. Ardından 18 -23 Ekim 1923 tarihlerinde kısa bir süre içerisinde dörtlüyü bestelemiştir.17 Ekim 1924 tarihinde Bohemian Quartet ile prömiyeri gerçekleşmiştir [Karel Hoffmann (Birinci keman), Josef Suk (ikinci keman), Oskar Nedbal (violist), Hanuš Wihan (viyolonsel)]. ${ }^{17}$

Janacek, Rus Edebiyatı'na hayrandır. Ancak Tolstoy'un öyküsünde Janacek'in ilgisini çeken kısım cinsiyet eşitsizliği hakkında oluşudur. Janacek'in görüşüne göre kadınlar toplumda haksızlığa uğramakta ve erkeklerin emrinde bulunmaktadır. Anthony Burton'un görüşüne göre Janacek, kadın bakış açısını temsil etmek için Kreutzer Sonat motiflerine dönmüş olmalıdır. O zamanlar Janacek kendisinden 37 yaş küçük, evli bir kadın olan Kamila Stösslová'ya karşıııksı olarak âşıktır. Janacek kendi kuartetini Kamila'ya adamıştır. 1924 yılında "Ekim" dergisinde yayınlanan ve Kamila'ya yazılan mektupta Janacek, kendi hikâyesini yazarken kötü davranılan, vahşice dövülen ve sonunda öldürülen zavallı bir kadını anlatmıştır. Kreutzer'in prömiyerini yapan Bohemian Quartet'inbir parçası olan, Çek besteci ve kemancı Josef Suk'a göre, Janacek kendi quartetini erkekler tarafından kadınlara gösterilen despot davranışlara karşı bir protesto olarak yansıtmıştır. ${ }^{18}$

Böylece, Tolstoy'un durumunda olduğu gibi, Janacek'in eserinde de topluma gönderilen bir mesaj olduğu tahmin edilmektedir. Nasıl bir eserdir ki Beethoven'ın Kreutzer Sonat'ı Tolstoy'u etkileyerek bir dünya klasiği eser doğuyor ve Tolstoy'dan etkilenen Janacek'le başka klasik oluşturabiliyor. Bunun bir başka örneği de Rene-Xavier Prinet'dir.

1901'de bitmiş tablo da Tolstoy'la Beethoven'ın eserinin birleşmiş ve ateş gibi yanan şehvetini gözler önüne sunmuştur. Ölümsüzleşmiş tablo da kemancı Trukachevsky ve Pozdnyshev'ın piyanist eşinin tutkulu öpücüğü, Rene-Xavier Prinet'in gözünden büyük bir hazzın ve şehvetin sonucu olan vahşi ve güçlü fiziksel isteklerin Kreutzer Sonat'ın

\footnotetext{
${ }^{17}$ Micheal Beckerman, Janacek as Theorist, New York, 1994, s.112.

${ }^{18}$ Beckerman, a.g.e., s. 112.
}

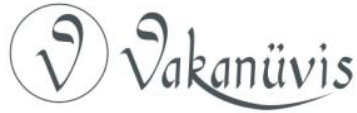


birinci bölümünün dinamiğinin ve karmaşıklığının birleşmesi anlatılmaktadır.

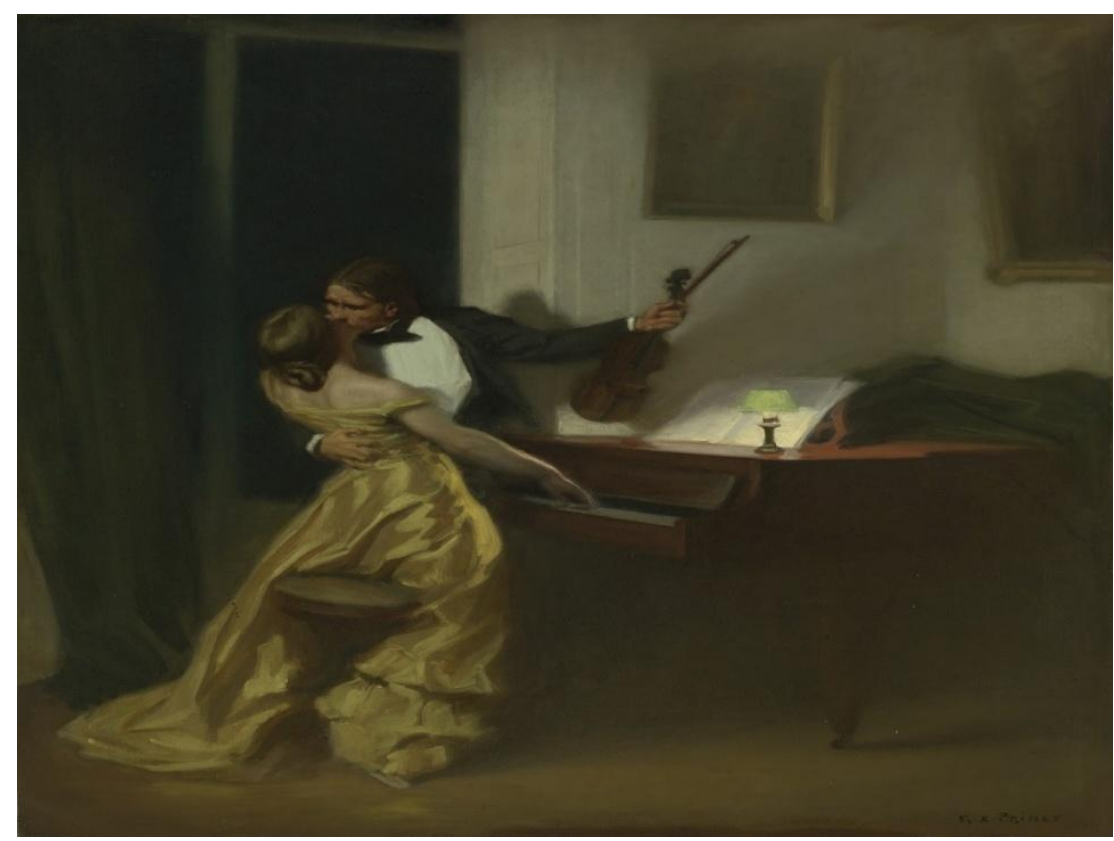

Şekil 4: Xavier Prinet'in 'Kreuzer Sonata' tablosu. ${ }^{19}$

Tabloda, Beethoven'ın birinci bölümünde yansıtılan kargaşa ve karışıklığın kişileştirilmesi ve aynı zamanda cinsel çekicilikle meydana gelen vahşi arzular Prinet tarafından yorumlanmıştır. Prinet'nin tablosunda, Pozdnyshev'ın vahşice kıskançlık nöbetinde olduğu ve korku içerisinde Truhaçevskiy'in kaçmasına izin verdiği ve kendi eşini ölümcül bir şekilde yaraladığı gösterilmektedir. Aynı zaman da tablo da Beethoven'ın "Kreutzer Sonat"। gibi Tolstoy'un da "Kreutzer Sonat"। görülmekte ve bu da onu eşsiz ve büyüleyici yapmaktadır.

1901 yılında Beethoven ve Tolstoy'un Kreutzer Sonatı'ndan etkilenerek hayata geçirdiği "Kreutzer Sonat" tablosu büyük bir beğeni toplayarak tarihte ölümsüzleşmeyi başarmıştır. 1901 yılında ilk defa

19 http://www.sothebys.com/en/auctions/ecatalogue/2011/19th-century-europeanart-n08783/lot.26.lotnum.html Erişim Tarihi: 10 Ocak 2018.

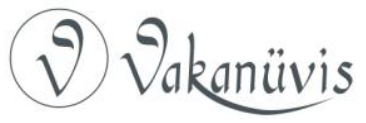


Paris, Munich ve Stuttgart da sergilenen tablo Bavyera prensi tarafından satın almıştır. Aynı zaman da bu tablo Prinet'in en popüler tablosu olarak tarihe geçmiştir.

\section{Sonuç}

Kreutzer Sonat gerek bir sonat ismi gerek bir edebi eser ismi olarak yüzyıllar boyunca varlığını sürdürmüştür. Ancak bu makale iki farklı sanat dalında iki ayrı esere ve de ondan sonra gelen birçok esere başlık olmuş bu ismin (Kreutzer Sonat) gerek sanatsal gerek düşünsel gerek ilerleme açısından muhakkak ki çeşitli biçimlerde etkileşim içinde olduğunu göstermektedir. Bu makale bilinen, yazılan çeşitli anlatımlar, hikâyeler, yorumlar ve araştırmalara dayanarak aradığımı bağları ortaya koymaya çalışmıştır ve de görüyoruz ki bu bağlar tesadüfi değil, sanıldığı kadar romantik de değil aksine, çok daha profesyonel çok daha bilinçli ve istemli, sanatsal becerilerin birbirilerini etkileyerek sanatın ilerlemesinde yol açmaya devam eden bir gelişme olduğunu irdelemiştir. Belki de arkasında birçok tesadüflerin yattığı, ancak bu tesadüflerin sanatçı duyarlılı̆ıyla doğru değerlendirilerek belli bir yöne doğru itilerek düzenlendiği ve gerçekten sanat hayatındaki devrimler toplamının gelecek nesillere ışıklı bir yol çizdiğinin tespitidir. İster Beethoven'ın Kreutzer Sonatı ister Tolstoy'un Kreutzer Sonat'ı bu yolu kendi çağlarını aşarak döşemişlerdir. Bu makaleye temel olan Beethoven ve Tolstoy'un Kreutzer Sonatları'nın birçok dalda ki yansımaları da incelenmiştir. Bu çalışmalar da öngörümü doğrular bir biçimde yazdığımı desteklemektedir.

\section{Kaynakça}

Antoniacci, Aliandra, The Crisis of the Russian Family in the Works of Dostoevsky, Tolstoy and Chekhov, Canterbury Üniversitesi Rusya Araştırmaları Enstitüsü Basılmamış Doktora Tezi, Canterbury 2015, s. 266.

Beckerman, Michael Brim, Janáček as Theorist. New York, 1994.

Flood, Alison, Sofia's revenge: short stories by Leo Tolstoy's wife and son are published with The Kreutzer Sonata, https://www.theguardian.com/books/2014/oct/30/sofia-tolstoy-kreutzersonata-variations-published-in-english (14 Ocak 2017).

G-Ken, Anton, Beethoven Jizn', Lichnost', Tvorchestvo, Saint Petersburg, 1910.

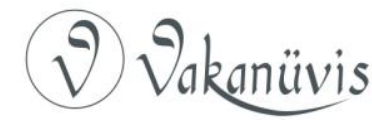


Göttsche, Dirk, Remembering Africa The Rediscovery of Colonialism in Contemporary German Literature, New York, 2013

http://www.classicfm.com/composers/beethoven/guides/key-people-

beethovens-music-and-life/kreutzer-sonata-beethoven/ Erişim Tarihi: 03 Ocak 2018.

http://www.sothebys.com/en/auctions/ecatalogue/2011/19th-centuryeuropean-art-n08783/lot.26.lotnum.html (10 Ocak 2017).

Isabel, Hapgood, "Tolstoi's Kreutzer Sonata", Nation, 50, (1890), s.

Kirillina, Larissa, Beethoven. Moskova, 2015.

Kirillova, Svetlana, Kreutzer Sonata, İskusstovo No.24, 2007.

Lockwood, Lewis, Beethoven: Müzik ve Hayat. Ebru Kılıç (Çeviren). İstanbul, 2013.

Moller, Peter UIf, Postlude to The Kreutzer Sonata : Tolstoy and the Debate on Sexual Morality in Russian Literature in the 1890's, Leiden, New York : E.J. Brill, 1988.

Nikolay, Gudziy, Lev Tolstoy Kritiko-biograficheskiy ocherk. Moskova, 1960.

Oswin, Matthew Beethoven's 'Kreutzer' Sonata: Nineteenth-century Art of Arrangement-One Piece Three Ways, New Zealand, 2013

Stroganova, Anna, "Neizdannaya povest' Sofyi Andreyevny Tolstoy "Ch'ya vina?» v novom literaturnom sezone", http://ru.rfi.fr/kultura/20100823neizdannaya-po1vest-sofi-andreevny-tolstoi-chya-vina-v-novom-literaturnom - sezone (14 Ocak 2010).

Tolstoy, Lev, Kroyçer Sonat Ergin Altay (Çeviren), İstanbul, 2015,

Tolstoy, Sergey, Ocherki bylogo. Moskova, 1965.

Tolstoya, Alexandra, Otec. Jizn' L'va Tolstogo. Moskova, 2001.

Tolstoya, Sophia, Moya jizn'. Moskova, 2014.

Wingfield, Paul, "Janáček's 'Lost' Kreutzer Sonata", Journal of the Royal Musical Association, 112/2, (1987), s.229-256

Yemelyanova, Irina, Muzyka v jizni L'va Nikolayevich Tolstogo, http://muzruk.info/?p=5152 (14 Ağustos 2017). 